\title{
El Chalet del Coronel: influencias inglesa y neovasca en Jerez de la Frontera (Cádiz)
}

\author{
María Isabel Serrano Macías \\ Universidad Pablo de Olavide de Sevilla \\ maribelserranomacias@gmail.com
}

RESUMEN: El Chalet del Coronel es una vivienda dentro de la antigua finca La Parra de Jerez de la Frontera, ubicada a diez kilómetros del centro de la ciudad, en los terrenos pertenecientes al actual Aeropuerto de La Parra. Su historia pasa de ser un proyecto de un miembro de la familia Domecq como residencia para su familia, a alojamiento de altos cargos del ejército español tras la Guerra Civil. Siendo un ejemplo de arquitectura de influencia neovasca e inglesa, y atribuida al arquitecto Luis Gutiérrez Soto, en la actualidad no existen investigaciones que ahonden en el análisis de la finca y la vivienda. Esta investigación es un primer estudio de la finca y del chalet, como ejemplo de arquitectura de influencia inglesa en la ciudad de Jerez de la Frontera y posible proyecto desconocido del arquitecto Gutiérrez Soto.

PALABRAS CLAVE: Arquitectura española; Estilo neovasco; Estilo victoriano; Gutiérrez Soto; Jerez de la Frontera; Familia Domecq.

\section{Colonel's House: English and Neobasque Influences in Jerez de la Frontera (Cadiz)}

ABSTRACT: The Colonel's House is a home located inside the estate La Parra, in Jerez de la Frontera, ten kilometres from the centre of the city. At the present time this estate belongs to La Parra Airport. It was originally conceived as a home for a member of the Domecq family before housing high ranking officers of the Spanish army after the Civil War.lt is a example of the influence of the Neobasque and English architecture, assigned to Luis Gutiérrez Soto. Currently the main building is derelict and it has no urbanistic protection. This research is a first study about the estate and the main house as an example of the influence of English architecture.

KEYWORDS: Spanish Architecture; Neobasque Style; Victorian Style; Gutiérrez Soto; Jerez de la Frontera; The Domecqs.

Recibido: 25 de abril de 2017 / Aceptado: 11 de agosto de 2017.

\section{Introducción}

En las instalaciones del actual Aeropuerto de Jerez de la Frontera se encuentra una casa abandonada protegida por un cercado que contrasta con el resto del entorno, comúnmente llamada Chalet del Coronel. Dicha vivienda y la finca donde se ubica, La Parra, están unidos a la historia de una de las familias jerezanas más ilustres, los Domecq Núñez de Villavicencio, y posteriormente a la creación del actual Aeropuerto de La Parra de Jerez. A finales del siglo XIX y principios del XX, Jerez estaba rodeado en su periferia por numerosas fincas suburbanas que servían de recreo y segunda residencia a las familias acomodadas de la ciudad. Muchas de estas fincas se construían en terrenos dedicados a viñas o para pacer el ganado. Este fue el caso de la Finca La Parra. Las fincas de recreo suburbanas en Jerez se construían según las normas estilísticas del momento, en las que predominaban las corrientes historicistas del siglo XIX, y en las que la influencia de la arquitectura victoriana inglesa tenía un alto grado de protagonismo en muchas de ellas. La arquitectura inglesa a la que nos referimos es la desarrollada en Reino Unido desde la segunda mitad del siglo XIX hasta los primeros años del siglo XX, y que fue tomada como modelo para realizar nuevas construcciones o remodelaciones en diferentes países europeos y colonias del

Cómo citar este artículo: SERRANO MACÍAS, María Isabel, «El Chalet del Coronel: influencias inglesa y neovasca en Jerez de la Frontera (Cádiz)”, Boletín de Arte-UMA, n. 38 , Departamento de Historia del Arte, Universidad de Málaga, 2017, pp. 149-160, ISSN: 0211-8483, DOI: http://dx.doi.org/10.24310/BoLArte.2017.v0i38.3384 
resto del mundo. El estilo victoriano, en sus variantes de Old English, Queen Anne, o estilo Neogótico, entre otros, fueron adoptados por los arquitectos que trabajaron en la época para dar gusto a la pujante burguesía que se estaba enriqueciendo cada vez más con sus negocios y que deseaban vivir a la moda, mezclándolo con otros estilos y dando lugar a construcciones eclécticas. En el caso de España, fueron desarrolladas en diferentes territorios de la península, como en el País Vasco o Cantabria (Paliza, 1987; Sazatornil, 2005), la provincia de Huelva (González, 2000), en el Campo de Gibraltar (Aranda, 2007), y en el territorio que nos ocupa, Jerez de la Frontera.

El gusto por la arquitectura victoriana británica en Jerez se produce por dos razones principales. La primera tiene como protagonista al vino de Jerez, que atrajo a la zona a inversores provenientes de las Islas Británicas esperando hacer fortuna en el mundo vitivinícola y continuar con el comercio que desde el siglo XV se daba entre los dos países. Estos se mezclaron con la alta sociedad de la zona creando lazos familiares e influyendo en la clase adinerada de la ciudad, cuya consecuencia fue un círculo social de alto poder adquisitivo que vivían a caballo entre Reino Unido y España. Esta nueva sociedad anglófila, mezcla de aristócratas y burgueses, adaptó a su modo de vida algunas costumbres inglesas relacionadas con los deportes, la cultura o la educación e hicieron edificios acordes a este gusto inglés. Para ello contaron con arquitectos británicos o con arquitectos locales instruidos en estas nuevas corrientes. Por otro lado, las familias adineradas jerezanas estaban al tanto de las corrientes arquitectónicas imperantes en Europa gracias a su difusión a través de revistas especializadas en arquitectura, y querían adaptar sus viviendas a la moda del momento. En Jerez encontramos ejemplos de esta influencia en diferentes edificios como el proyecto que encargó Manuel María González Ángel en la Quinta de la Alameda, al arquitecto británico John Prichard en 1864 o algunas fincas como el Recreo El Altillo o el Recreo Warter, ambas del último tercio del siglo XIX. A principios del siglo XX, encontramos otras obras como el Pabellón del Jockey Club de 1905, obra de Francisco Hernández-Rubio, o el Barrio Obrero de 1904 promovido por Luis de Ysasi Lacoste.

Aunque el Chalet del Coronel es algo tardío por la fecha en que fue construido, responde a este gusto por incorporar elementos de la arquitectura victoriana a las nuevas construcciones. El arquitecto proyectó una vivienda reflejo de la influencia de la arquitectura doméstica anglosajona correspondiente a esta época victoriana comentada. Este trabajo pretende dar a conocer un edificio que forma parte de una etapa arquitectónica de la historia de Jerez desconocida para muchos, y deja abierta una puerta para futuras investigaciones que completen su historia.

\section{Historia de la Finca La Parra y consideraciones sobre el arquitecto del proyecto}

La Finca La Parra está situada a diez kilómetros del centro de la ciudad. Estos terrenos, anteriormente denominados Dehesa de la Parra, estaban ubicados dentro del sitio de Caulina, en el término de Jerez de la Frontera ${ }^{1}$. Junto a la finca, a unos ochocientos metros, se encontraba el apeadero de La Parra, la estación de ferrocarril más cercana, y conectaba a la finca con Jerez y Sevilla. Se accedía a él desde la casa mediante una carretera directa ${ }^{2}$ [1]. Este apeadero desapareció a mediados de los años noventa del siglo XX y en la actualidad existe una nueva estación que conecta el aeropuerto con la ciudad.

Según unos documentos de 1908 y $1917^{3}$, la finca era propiedad de la familia Domecq Núñez de Villavicencio. En concreto la gestionaban Pedro Domecq Núñez de Villavicencio y su hermano Manuel Domecq Núñez de Villavicencio ${ }^{4}$. Manuel Domecq estaba casado con María de las Mercedes González Gordon, hija de Pedro Nolasco González de Soto, por lo que con este matrimonio se unen dos de las familias vinateras más importantes de Jerez, los Domecq y los González ${ }^{5}$. Uno de sus trece hijos, Pedro Francisco Domecq y González, fue quien encargó en 1929 la construcción de la casa que nos ocupa con el fin de trasladarse a vivir allí con su familia (Oteo, 2014: 30).

Hasta la fecha, no se han podido localizar los planos de construcción de esta casa, pero sí se han consultado otras fuentes que aportan datos sobre el posible arquitecto del proyecto. Según unos documentos del Archivo Histórico del Ejército del Aire ${ }^{6}$, el arquitecto que realizó las obras fue Manuel Gutiérrez Soto, pero los datos que se aportan sobre su biografía (fue Capitán de Obras de los servicios de Aviación, autor del Cuartel General del Ejército del Aire o jugador del Real Madrid) corresponden al conocido arquitecto Luis 


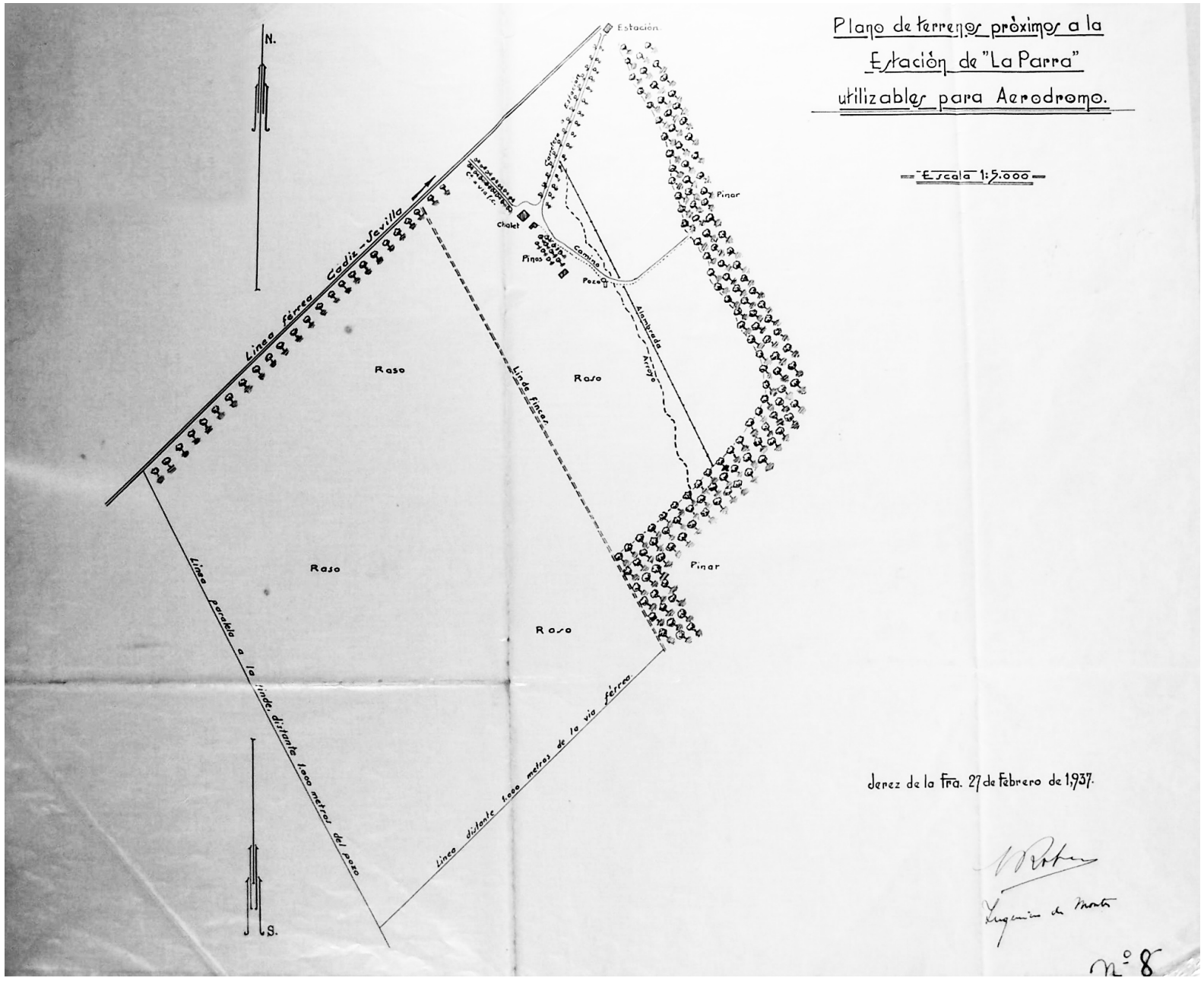

1. Plano de terrenos próximos a la Estación de La Parra utilizables para el Aeródromo, 1937. Fuente: Archivo Histórico de Jerez de la Frontera

Gutiérrez Soto, por ello entendemos que hubo un error en el nombre de pila. Según estos documentos, en 1929 se le encargaron al arquitecto un conjunto de construcciones por parte de la familia Domecq ${ }^{7}$. Sabemos que Gutiérrez Soto realizó varios trabajos en Jerez (Aroca, 2000: 433-434), aunque no consta en las publicaciones existentes que hiciera ningún proyecto en estas fechas en la ciudad, hasta diez años más tarde, realizando las obras del Aeródromo de La Parra (Anónimo, 1971: 63). Por lo tanto, si el arquitecto fue Gutiérrez Soto, esta casa sería una de las primeras que hizo tras acabar la carrera de Arquitectura. Gutiérrez Soto trabajó para la alta burguesía y realizó numerosos encargos de chalets y casas de campo (Baldellou, 1973: 79-84; Anóni- mo, 1971: 61-64). Era famosa su soltura y maestría para trabajar con cualquier estilo arquitectónico (De San Antonio, 1996: 501-502), incluidos los historicismos (Baldellou y Capitel, 1996: 379) por lo que es probable que proyectara esta vivienda también para Pedro Domecq y González. No obstante, tomaremos con la prudencia que se merece este dato hasta poder contrastar la información y dejamos abierta esta línea para futuras investigaciones.

A partir de 1937 la historia de la finca transcurre paralela al proyecto de construcción del nuevo Aeródromo de Jerez de la Frontera. Durante la Guerra Civil española, un grupo de acomodados jerezanos formaron una comisión con el fin de recaudar dinero y colaborar así con las tropas del Bando 
Nacional (Esquerdo y Jiménez, 1993: 41; Utrilla, 2006: 5051), consiguiendo una recaudación de un millón doscientas mil pesetas. El destino de este dinero era la compra de un avión cuyo nombre sería Jerez y que combatiría del lado de los nacionales. Finalmente el dinero se empleó en un proyecto menos perecedero, la compra de un terreno para ubicar un aeródromo. El día 5 de mayo de 1937, aparece publicado en el diario Ayer que se empezarían las obras de la Escuela de Aviación de Jerez gracias a la aportación que la ciudad había hecho para ello ${ }^{8}$.

Entre las fincas que pasaron a formar parte de las instalaciones del Aeródromo, estaba la Dehesa La Parra. Esta fue comprada previa segregación del resto de la dehesa a los señores Domecq y González el 14 de febrero de 1947 ante el notario Don Ramón Moreno Palacios ${ }^{9}$. A partir de este momento los terrenos de La Parra pasaron a formar parte de las instalaciones de la Base Aérea de Jerez, usándose la vivienda principal como residencia de los oficiales del Ejército del Aire ${ }^{10}$ hasta que en 1993 se cerró esta base y se trasladó a Morón de la Frontera (Sevilla).

Desde entonces, las instalaciones son gestionadas por AENA ${ }^{11}$, y la vivienda ha quedado sin uso. Hubo un proyecto de rehabilitación y adecuación del edificio en febrero del 2009 por parte de la Empresa Municipal de Suelo del Ayuntamiento de Jerez ${ }^{12}$. Se redactó un informe y se elaboraron planos de la vivienda para su estudio, pero nunca llegó a realizarse esta rehabilitación.

\section{El Chalet del Coronel: arquitectura inglesa y neovasca en Jerez}

Como hemos comentado, la vivienda y algunos elementos de sus inmediaciones parece ser que fueron encargados a Luis Gutiérrez Soto en 1929. En estos años se estaba desarrollando en España una vertiente estilística ligada al regionalismo vasco, la arquitectura neovasca, entre los años 1910 y 1930 (Paliza, 1985-86: 232), inspirada en los caseríos vascos rurales y tomada por la pujante burguesía del lugar como estilo predilecto para sus nuevas viviendas. Deseaban que sus proyectos siguieran las normas estilísticas de las corrientes arquitectónicas que estaban imperando en Europa, adoptando así también el estilo inglés en sus encargos. La relación entre el País Vasco e Inglaterra era igual de estrecha que la que tenía Jerez con el país británico, debido al comercio y la minería. Estos estilos, neovasco e inglés victoriano, fueron los elegidos para el encargo de Pedro Domecq y González. La familia del señor Domecq y González había consolidado años atrás sus relaciones comerciales con Inglaterra gracias al negocio del vino. Tanto la familia Domecq como la familia González adoptaron en su modo de vida este gusto inglés que tan de moda estaba entre la clase adinerada, llegando incluso a educar a sus hijos en colegios ingleses o tener segundas residencias en las Islas Británicas. Todo esto hace pensar que Pedro Domecq y González quisiera que su nueva vivienda estuviera influenciada por este gusto inglés y por la corriente regionalista que imperaba en esos años.

La Finca La Parra contaba con una vivienda principal, una casa merendero, la casa del encargado (que años más tarde se convirtió en capilla), y otros elementos como dos casitas de chapa y alojamiento para animales, almacén e incubadora, además de la escultura de un crucificado llamado Cristo de la Parra ${ }^{13}$. En este artículo vamos a centrarnos en el análisis de la vivienda principal, el Chalet del Coronel, ya que es la que ejemplifica esta influencia de la arquitectura inglesa.

El Chalet del Coronel domina todo el conjunto [2]. Es una construcción de dos plantas con una cubierta abuhardillada y un torreón. Exteriormente, el revestimiento de la fachada en la planta baja está pintado de blanco con almohadillado rematando las esquinas. La puerta principal se encuentra enmarcada por un pequeño porche adintelado sobre pilares, también enmarcado con almohadillado. En la planta superior, la fachada está decorada con un entramado de madera ficticio, de líneas geométricas que abarcan también la fachada de la cubierta abuhardillada. Encima del porche se abre una pequeña terraza con un antepecho de listones de madera. Los vanos de la casa son rectangulares, formados por paneles de cristal sobre montantes de madera, aunque en la actualidad los de la planta baja están tapiados. La cubierta es de teja curva, muy deteriorada por el paso del tiempo, y parece ser que en sus inicios era de color rojo ${ }^{14}$. La casa tiene una planta en forma de $L$ donde sobresalen los volúmenes del torreón y de los dos cuerpos de la fachada principal correspondientes a las habitaciones que flanquean la terraza y el porche, todos con pequeñas ventanas que proporcionan luz al interior de la buhardilla. 


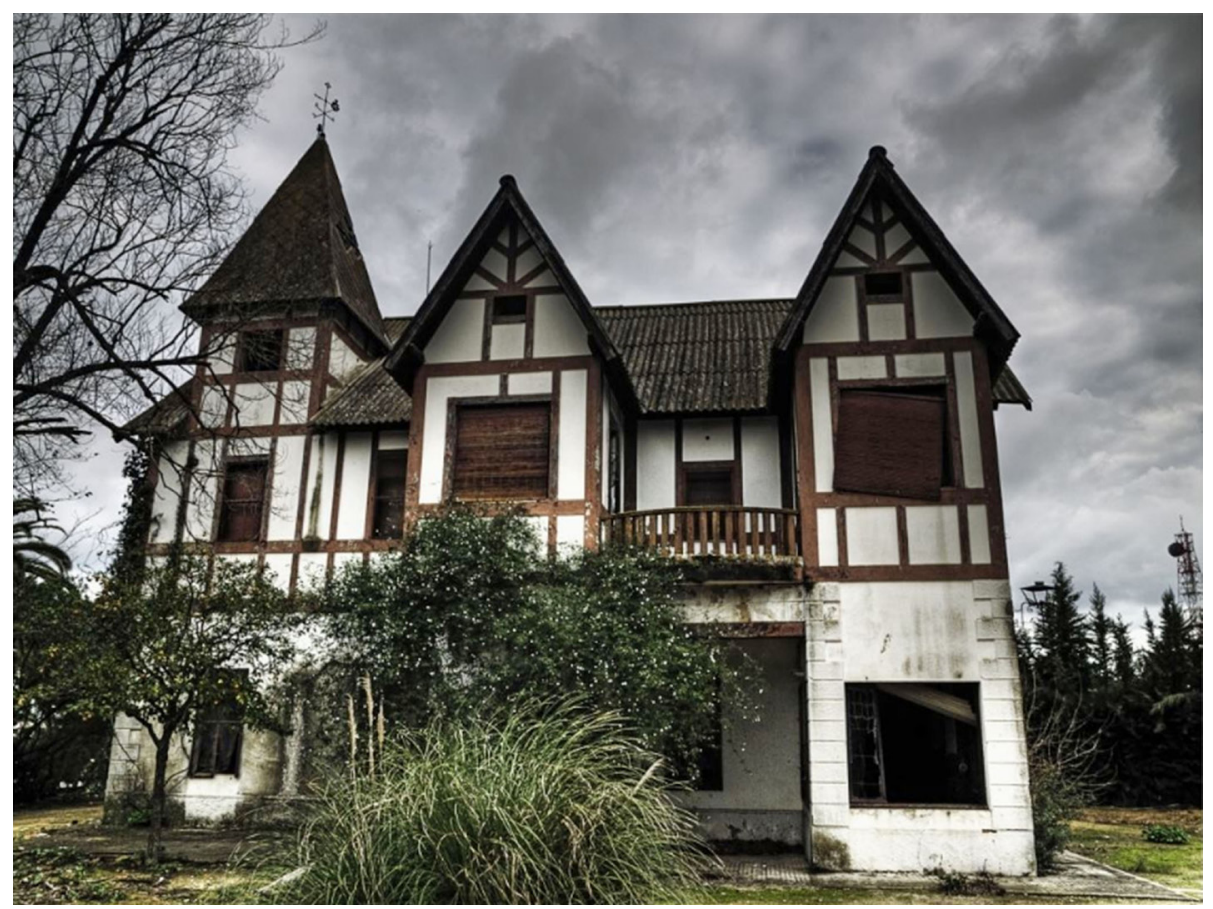

2. Fachada principal del Chalet del Coronel. Fuente: web Abandonalia

La influencia de la arquitectura victoriana inglesa la encontramos en varios de estos recursos utilizados para componer la fachada. Por un lado la asimetría de los cuerpos y volúmenes. Vemos el uso del torreón, que destaca sobre el resto de la cubierta, o los dos cuerpos adelantados de la fachada principal con hastiales triangulares que rompen la horizontalidad de esta (Paliza, 1987: 67-68). El uso del almohadillado de las esquinas y el falso entramado de madera sobre revestimiento pintado de blanco de los pisos superiores son recursos muy utilizados tanto en la arquitectura victoriana, en su vertiente Old English, como en la arquitectura neovasca (Paliza, 1985-86: 234). Las ventanas compuestas con paneles de cristal sobre montantes de madera y el uso de contraventanas también poseen el toque anglosajón del que hablamos.

Con respecto al interior de la vivienda, vemos una clara diferenciación entre la zona de los señores de la casa y la del servicio doméstico, que corresponde fielmente al concepto de segregación de los grupos que habitan una vivienda de estas características, uno de los ideales de la arquitectura doméstica victoriana (Girouard, 1979: 28). En la planta baja [3] encontramos la zona de los señores. A esta se accede por una puerta principal (A) que se encuentra enmarcada por el porche (estancia 1) que da acceso al hall (estancia 2). El hall actúa como elemento distribuidor del espacio, dejando independiente las estancias de la planta. Por el lado derecho se accede al salón principal (estancia 3) y por el lado izquierdo a otra sala un poco más pequeña (estancia 6). En el hall también está el acceso a la planta primera a través de la escalera principal de madera (B) y un aseo bajo ella (estancia 5). Las paredes están forradas con papel pintado con decoración vegetal y revestimiento de madera. Además, el hall conecta con el distribuidor (estancia 7) del que hablaremos más adelante. El hall fue uno de los elementos más importantes de la arquitectura doméstica en Inglaterra en el siglo XIX. El hecho de que en esta vivienda se accediera a él a través de un porche, y que el arquitecto lo usara como distribuidor de las estancias de la planta baja y como arranque de la escalera principal, demuestra que era conocedor de esta circunstancia y pretendía hacer el interior de la casa siguiendo las pautas de esta corriente anglosajona.

El salón principal (estancia 3), al lado derecho del hall, es una gran sala de cincuenta y ocho metros cuadrados, con 


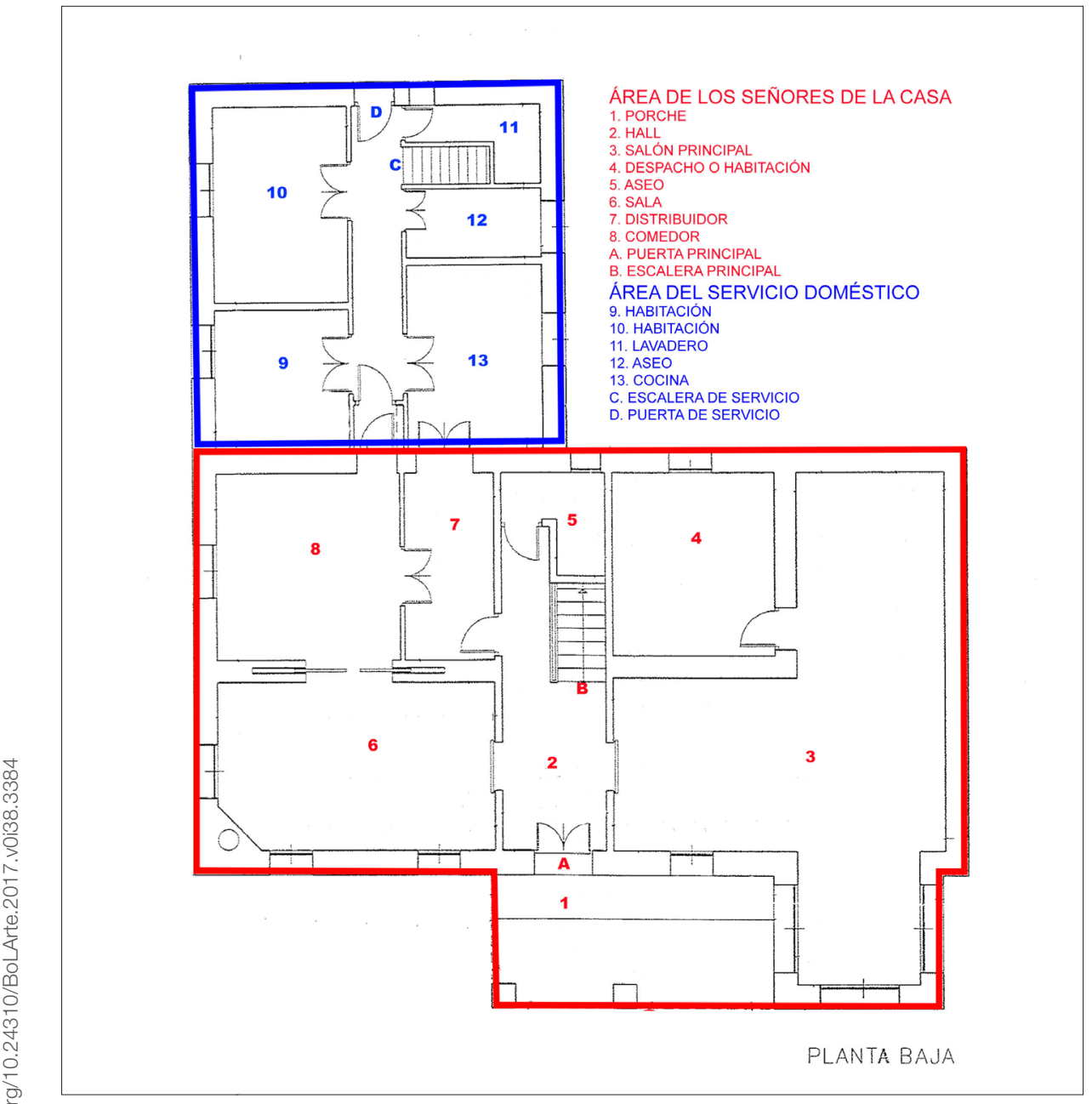

3. Plano de la planta baja del Chalet del Coronel. Fuente: elaboración propia con plano del Informe de rehabilitación y adecuación del edificio (AENA) como base planta en forma de T, la cual organiza varios espacios y crea diferentes ambientes [4]. En el lado más largo tenemos en un extremo una zona presidida por una gran chimenea de ladrillo rojo y madera. La campana de la chimenea, revestida de madera, esta decorada con un tondo en cuyo interior encontramos un escudo en bajo relieve. Este escudo está formado por dos blasones de medio punto con una corona en su parte superior, que por sus características y el título nobiliario que poseía el dueño de la casa, podría corresponderse con la tipología de la corona de vizconde. Los blasones no han podido ser identificados, ya que las imágenes disponibles de esta chimenea no permiten su identificación, pero deben estar relacionados con los propietarios de la casa. Junto a ella hay un ventanal rectangular de paneles de cristal con vistas al exterior de la casa en su lado suroeste. El lado opuesto de la sala lo compone un espacio más pequeño, con ventanales rectangulares en tres de sus lados y en el que se ubica un banco de madera corrido que permite disfrutar de la luz y las vistas del exterior de la casa en su lado noroeste, a modo de bay window ${ }^{15}$. El lado más corto de la estancia es una zona libre por donde está el acceso al hall. Todas las paredes de la estancia están revestidas de madera pintada de negro hasta un metro de altura aproximadamente decorada con casetones que conecta con la decoración de la chimenea. El techo de la sala está coronado por vigas de madera con decoración vegetal y el pavimento es de suelo de loza. Esta opción del revestimiento de madera y el uso de vigas es otro de los recursos utilizados por el arquitecto para recrear los interiores domésticos ingleses (Paliza, 1987: 71). El salón conecta con una pequeña habitación a la que se accede por una puerta 


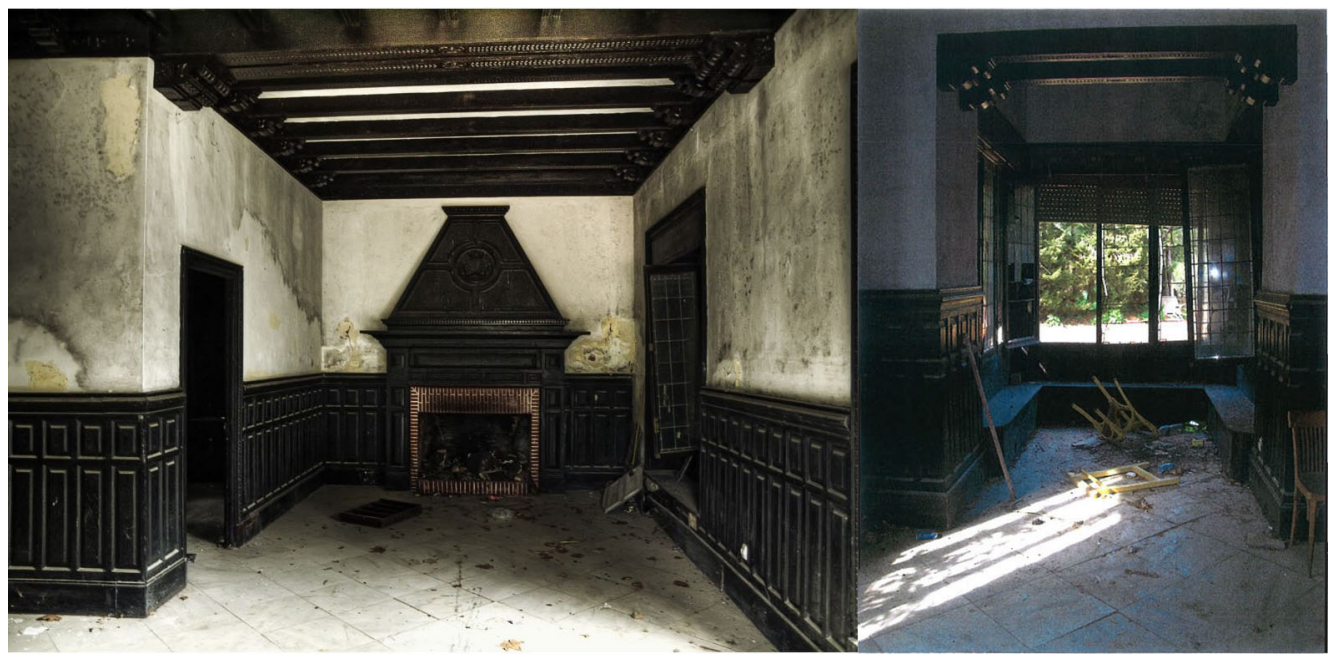

4. Salón principal del Chalet del Coronel. Fuente: web Abandonalia y AENA, respectivamente

junto a la chimenea. Es una habitación pequeña, con una ventana y que por su localización en la planta baja podría destinarse a despacho o biblioteca, zonas masculinas muy comunes en este tipo de viviendas (Paliza, 1987: 70).

Al lado izquierdo del hall, encontramos una sala de menores dimensiones de planta rectangular (estancia 6). Posee tres ventanas al exterior orientadas al norte, entre dos de las cuales se ubica una chimenea más sencilla que la anterior pero también de ladrillo y madera, haciendo esquina. Estas ventanas están formadas por contraventanas interiores de madera y paneles de cristal sobre montantes, también de madera. Al igual que el salón principal, las paredes están revestidas de paneles, el techo posee robustas vigas y el suelo es de loza. La sala conecta con unas puertas correderas con la siguiente habitación. Por sus características podría corresponderse con una habitación destinada a comedor principal.

Por las puertas correderas se accede a la siguiente sala (estancia 8), la cual, a su vez, conecta con el distribuidor por unas puertas dobles y con la zona de servicio por otra. El uso de esta sala podría haber sido el de segundo comedor, más sencillo, destinado a los desayunos y las comidas de los niños. El distribuidor (estancia 7) es una pequeña área que organiza el espacio y conecta la entrada principal o hall con lo que podría ser el comedor, siendo uno de los accesos por los que se entra también a la zona del servicio.
La zona de servicio es una ala de la vivienda de planta cuadrada, con una puerta independiente con salida al exterior orientada al sureste (D). Sus estancias están organizadas en torno a un pasillo longitudinal, y conecta con la planta superior a través de una escalera secundaria (C), evitando así usar la escalera de la zona de los señores. Posee cinco estancias, todas con ventanas al exterior: la cocina (estancia 13), aseo (estancia 12), lavadero (estancia 11) y dos habitaciones que podrían usarse como despensas de alimentos o almacenes de menaje del hogar, así como también zona de trabajo para el servicio (estancias 5 y 10).

Como vemos, cada estancia de la casa poseía un fin determinado, ya sea para uso de los señores o para uso del servicio doméstico. Este es otro de los ideales de la arquitectura victoriana, junto con la segregación, el de la especialización de las estancias. Normalmente las viviendas se dividían en cuatro grupos correspondientes a los señores, los niños, los invitados y el servicio. De esta manera cada grupo tenía su espacio y no tenía por qué mezclarse con el otro grupo si no era necesario. El hecho de poseer dos escaleras, una principal y otra para el servicio, también responde a estos conceptos de segregación y especialización de los que hablamos (Girouard, 1979: 28-29). Otro de los conceptos de la arquitectura británica que encontramos reflejado en este proyecto es el de privacidad. Separar al servicio doméstico del resto de la casa responde a este concepto. La escalera 


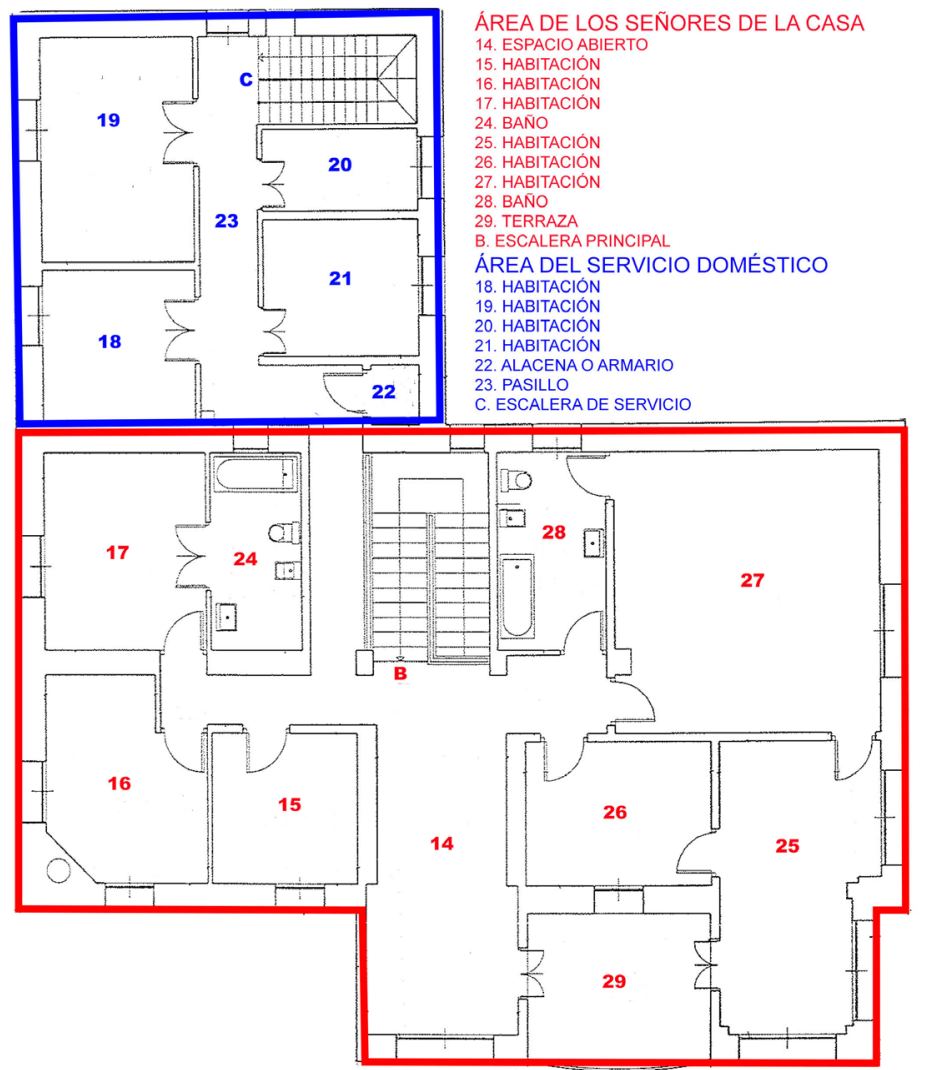

PLANTA PRIMERA
5. Plano de la planta primera del Chalet del Coronel. Fuente: elaboración propia con plano del Informe de rehabilitación y adecuación del edificio (AENA) como base de servicio separada de la principal o la puerta de salida al exterior fuera de la vista y ubicada en la trasera del edificio permiten que el servicio doméstico desempeñe sus funciones sin mezclarse con la familia que habita la vivienda. Se concibe a la familia como una comunidad y al servicio como otra (Kerr, 1871: 67-68; De Prada, 1998: 138).

A la planta superior [5] se accede tanto por la escalera principal como por la de servicio. En la zona de los señores hay dos áreas diferenciadas separadas por una estancia abierta (estancia 14) que distribuye el espacio y posee salida a la terraza (estancia 29). Esta estancia corresponde a uno de los volúmenes salientes de la fachada principal de la vivienda. En el lado derecho de la estancia se encuentra una habitación de grandes dimensiones de planta cuadrada (estancia 27) y con acceso a un baño completo (estancia
28). Esta habitación posee una segunda puerta por la que se accede a otra estancia rectangular (estancia 25) que, a su vez, conecta con la terraza y con una tercera habitación (estancia 26). Tanto el baño como esta tercera habitación tienen una puerta adicional de acceso al pasillo. Esta gran área de habitaciones conectadas entre sí podría corresponderse a los dormitorios de los señores de la casa, con diversas estancias destinadas a usos privados de ellos, o también como habitación de los niños. En este tipo de viviendas era común organizar las estancias de los niños conectadas entre sí, uniendo habitaciones para niños y niñas, sala de juegos, dormitorio para la institutriz (que a menudo era inglesa), y baño (Paliza, 1987: 71). Al otro lado encontramos tres habitaciones independientes de menores dimensiones (estancias 15, 16 y 17), en la que alguna podría destinarse a 


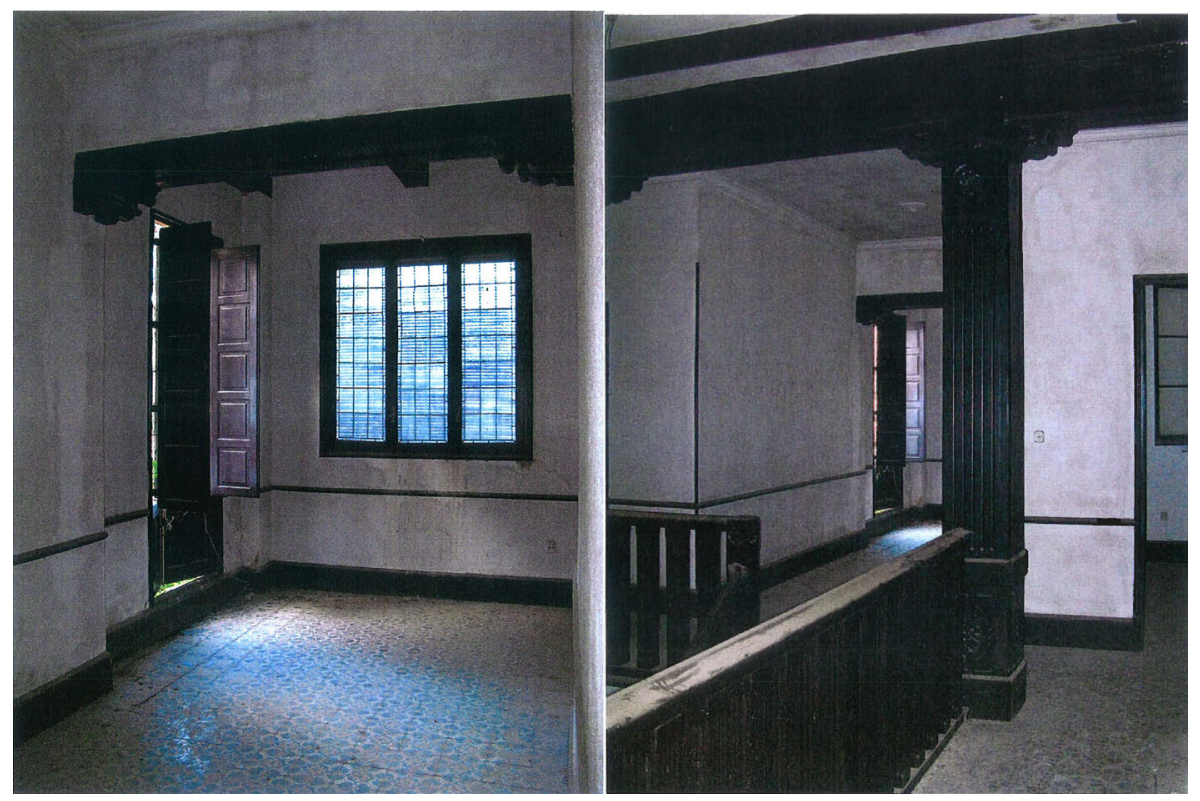

6. Interior de la planta primera del Chalet del Coronel. Fuente: AENA

invitados. Una de ellas podría tener chimenea (estancia 16) ya que observamos en el plano señalada una salida de humos, que corresponde a la misma salida de la chimenea de la planta baja (estancia 5). De las tres habitaciones, una de ellas es de mayores dimensiones (estancia 17) y posee baño completo propio, por lo que podría corresponderse con una habitación principal destinada a los señores de la casa o habitación de niños, con una tipología más simple.

Según las escasas imágenes existentes del interior de la planta alta [6], esta era más sencilla en decoración que la planta inferior. El pavimento era de losetas hidráulicas, con las paredes lisas pintadas de blanco y las estancias sólo decoradas con vigas y pilares de madera decorados siguiendo la misma línea que los de la planta baja.

La terraza (estancia 29) se encuentra ubicada entre los dos volúmenes salientes de la fachada principal. Es de pequeñas dimensiones y posee un antepecho ligeramente curvo realizado con listones de madera. Todas las habitaciones de la planta superior poseen salidas al exterior, ya sea por ventanas o puertas de acceso a la terraza. Son vanos sencillos, de madera y paneles de cristal, con persianas enrollables de color marrón.

A través de un pasillo próximo a estas tres habitaciones independientes, se puede acceder a la zona de servicio. Esta se distribuye en 4 estancias $(18,19,20$ y 21) y un pequeño habitáculo (estancia 22). Todas poseen ventanas al exterior, aunque es de señalar que no existe ningún baño, por lo que el servicio dispondría tan solo del aseo de la planta baja. Aunque normalmente el servicio ocupaba la planta baja, es común que en plantas superiores tuvieran dormitorios, si era servicio interno y permanente de la casa (Paliza, 1985-86: 233).

La escalera principal de la zona de los señores acaba en esta planta, pero la escalera de servicio continúa con un tramo más, dando acceso a la buhardilla [7]. La buhardilla (estancia 31) ocupa toda la superficie de la vivienda, siendo un gran espacio abierto con cuatro ventanas y una pequeña habitación que corresponde al interior del torreón (estancia 30). Por las imágenes de que disponemos del interior de la cubierta [8], parece que no está terminada o no se destinó a ningún uso.

Al igual que se aplican los conceptos victorianos de segregación, especialización y privacidad comentados anteriormente, el arquitecto también refleja en su composición del interior de la casa las condiciones de iluminación, ventilación e higiene necesarias para crear una casa confortable. Vemos que todas las habitaciones, tanto las de los señores como las del servicio doméstico poseen una o varias ventanas al exterior, permitiendo la iluminación natural y la 


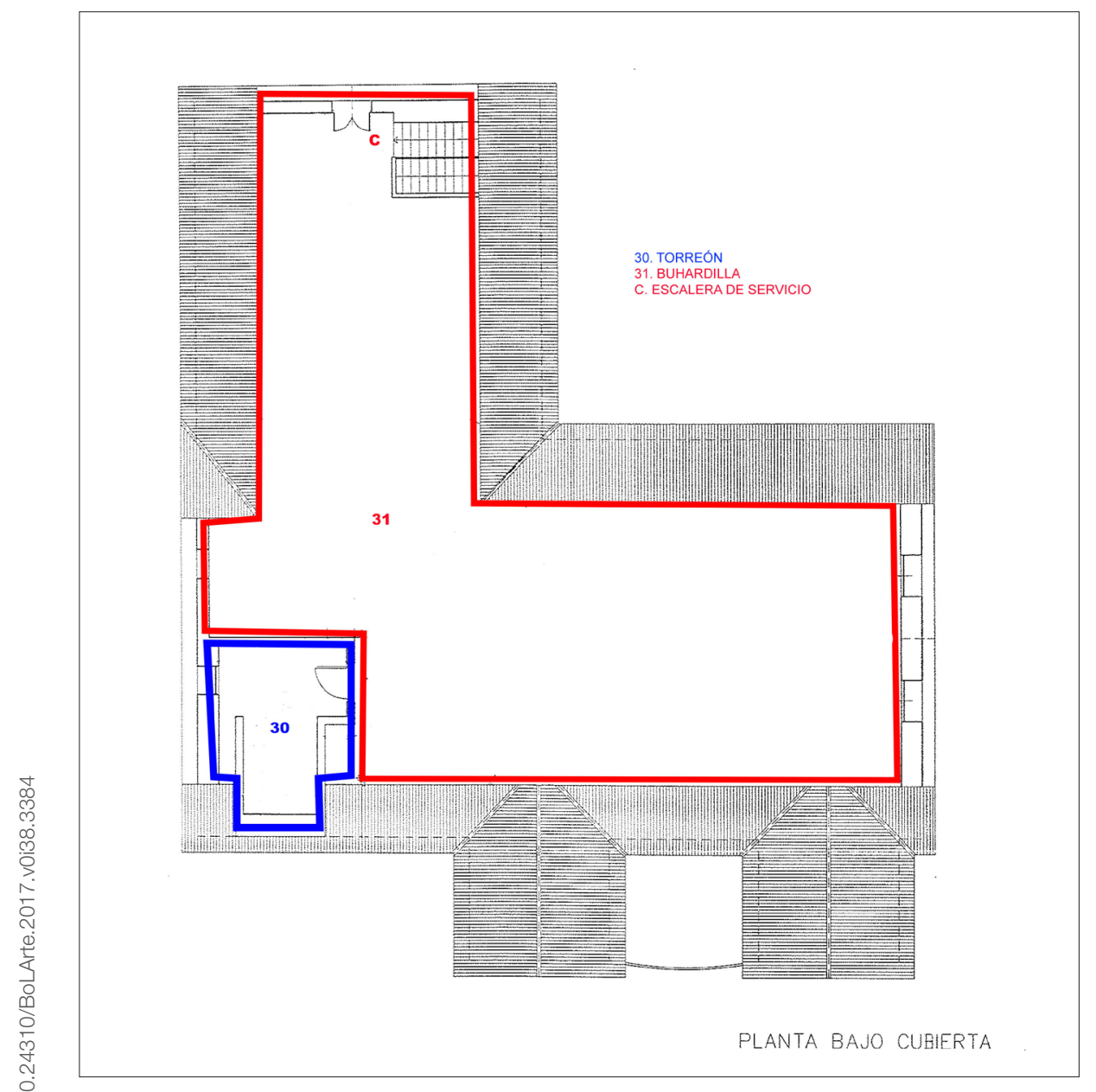

7. Planta bajo cubierta del Chalet del Coronel. Fuente: elaboración propia con plano del Informe de rehabilitación y adecuación del edificio (AENA) como base

8. Interior de la buhardilla de bajo cubierta del Chalet del Coronel. Fuente: AENA 
ventilación diaria. Por otra parte, la casa se construye alejada de vistas u olores desagradables que pudieran perturbar a la familia, como el de las cochineras, cuadras, gallineros o vaquería (Kerr, 1871: 78-79; De Prada, 1998: 138-139). Además posee un total de cuatro estancias de sanitarios, entre baños completos y aseos, completamente equipados y adaptados a los avances higiénicos del momento.
Este análisis se ha realizado bajo algunas limitaciones. El acceso a la vivienda no ha sido posible ya que su actual propietario ha negado el acceso debido al peligro que conlleva por su estado de abandono. Esto, unido a la escasa información encontrada sobre la vivienda, ha dificultado en gran medida la investigación. No obstante, se sigue trabajando en ello, dejando abierta una nueva línea de investigación.

\section{Notas}

1 Archivo Histórico del Ejército del Aire, Madrid (AHEA, Madrid), Sig. 358.4-14.

2 Archivo Municipal de Jerez de la Frontera (AMJF), Leg. 5429 Exp. 1281, Base Aérea La Parra, «Plano de terrenos próximos a la Estación de La Parra utilizables para el Aeródromo", realizado por un ingeniero de montes de firma ilegible, el 27 de febrero de 1937.

3 AMJF Leg. 0489 Exp. 12023 y Leg. 0490 Exp. 12086.

4 AHEA, Madrid. Sig. 358.4-14.

5 Propietarios de la bodega González Byass.

6 AHEA Sig. 358.4-14.

7 AHEA, Madrid. Sig. 358.4-14, pp. 280-281.

8 AMJF Diario Ayer, Notas de Alcaldía, 5 de mayo de 1937.

9 AHEA, Madrid. Sig. 358.4-14.

10 AHEA, Madrid. Sig. $2^{\circ}$ RA 854 , donde figura la finca numerada con los números 84-180 en un plano de la Base Aérea de Jerez realizado por el Ministerio del Aire y AHEA, Madrid, Sig. A11893.

11 Aeropuerto de Jerez, Historia. En: <http://www.aena.es/es/aeropuerto-jerez/historia.html> (fecha de consulta: 22-03-2017).

12 Informe facilitado por AENA.

13 AHEA, Madrid. Sig. 358.4-14.

14 AHEA, Madrid. Sig. A11893.

15 El bay window es una ventana mirador de planta poligonal, muy típico de las construcciones inglesas en el siglo XIX.

\section{Bibliografía}

ANÓNIMO (1971) «La obra de Luis Gutiérrez Soto. Obras y proyectos», Hogar y Arquitectura, n. o 92, pp. 61-64.

ARANDA BERNAL, Ana María (2007), La arquitectura inglesa en el Campo de Gibraltar, Diputación de Cádiz, Servicio de Publicaciones, Cádiz.

AROCA VICENTI, Fernando (2000), "Nuevas aportaciones a la obra de los arquitectos Luis Gutiérrez Soto y Antonio Sánchez Esteve», Laboratorio de Arte, n. ${ }^{\circ} 13$, pp. 433-442.

BALDELLOU, Miguel Ángel (1973), Gutiérrez Soto, Servicio de Publicaciones del Ministerio de Educación y Ciencia, Secretaría General Técnica, Madrid.

BALDELLOU, Miguel Ángel y CAPITEL, Anton (1996), Arquitectura española del siglo XX, Summa Artis, Historia General del arte XL, tomo 40, Espasa Calpe, Madrid.

DE PRADA, Manuel (1998), «El modelo funcional y la arquitectura libre inglesa», Cuaderno de Notas, n. ${ }^{\circ}$ 6, pp. 125-144.

DE SAN ANTONIO GÓMEZ, Carlos (1996), 20 años de Arquitectura en Madrid. La edad de plata: 1918-1936, Consejería de Educación, Madrid.

ESQUERDO, José Clemente y JIMÉNEZ CÓRDOBA, Juan Antonio (1993), «Medio siglo al servicio del Ejército del Aire. Base Aérea de Jerez", Revista Aeroplano, n. ${ }^{\circ} 11$, pp. 40-48.

GIROUARD, Mark (1979), The Victorian Country House, Yale University Press, Yale. 
GONZÁLEZ VILCHES, Miguel (2000), Historia de la arquitectura inglesa en Huelva, Secretariado de Publicaciones, Universidad de Sevilla. KERR, Robert (1871), The Gentleman's House: or, how to plan English Residences, J. Murray, Londres.

PALIZA MONDUATE, Maite (1985-86), «Estudios de la obra del arquitecto Manuel María Smith Ibarra», Kobie (Serie Bellas Artes), n. ${ }^{3}$, pp. 231-259.

- (1987), «La importancia de la arquitectura inglesa del siglo XIX y su influencia en Vizcaya», Kobie (Serie Bellas Artes), n. ${ }^{\circ} 4$, pp. $65-100$.

OTEO BARRANCO, Carmen (2014), Las lágrimas del vino: trazos de memoria de Manuel Domecq Zurita, Renacimiento, Valencina de la Concepción, Sevilla.

SAZATORNIL RUIZ, Luis (2005), "Ralph Selden Wornum y la arquitectura inglesa en la costa cantábrica», en CABAÑAS BRAVO, Miguel (coord.), El arte foráneo en España: presencia e influencia, Consejo Superior de Investigaciones Científicas, Madrid, pp. $149-165$.

UTRILLA NAVARRO, Luis y FERNÁNDEZ GARCíA, José (2006), Historia del aeropuerto de Jerez de la Frontera, Aena Centro de Documentación y Publicaciones, Madrid. 